Resi st ance associ at ed wi th measur ement s of capaci tance i n el ectri c doubl e I ayers

\begin{tabular}{|l|l|}
\hline 著者 & $\begin{array}{l}\text { Aoki Koi chi, Hou Yongdan, Chen Ji ngyuan, } \\
\text { N shi um Toy ohi ko }\end{array}$ \\
\hline $\begin{array}{l}\text { j our nal or } \\
\text { publ i cat i on t i t l e }\end{array}$ & Journal of El ect r oanal yt i cal Chemi st ry \\
\hline vol une & 689 \\
\hline page range & $124-129$ \\
\hline year & $2013-01$ \\
\hline URL & ht t p: //hdl . handl e. net /10098/7602 \\
\hline
\end{tabular}




\title{
Resistance associated with measurements of capacitance in electric double layers
}

\author{
Koichi Aoki ${ }^{*}$, Yongdan Hou, Jingyuan Chen, Toyohiko Nishiumi \\ Department of Applied Physics, University of Fukui, 3-9-1, Fukui, 910-0017, Japan
}

\begin{abstract}
The behavior of electric double layers at polarized interfaces in $\mathrm{KCl}$ solutions is revisited in order to examine properties of the constant phase element (CPE). We pay attention specifically to frequency dependence of both the capacitance and the resistance. Two parallel platinum wires immersed in solution are used as insulator-free electrodes. They avoid stray capacitance or irreproducibility of impedance caused by incompleteness of electric shield of electrodes. The Nyquist plot takes approximately a straight line because the in-phase component, $Z_{1}$, is inversely proportional to ac-frequency, similar to the capacitance. Since $Z_{1}$ extrapolated to zero separation of the electrodes is non-zero, a resistance is present at the double layer in parallel form. It is not a Faradaic resistance because of absence of any electroactive species. The parallel resistance is inversely proportional to the frequency, whereas the capacitance decreases with a linear relation to logarithm of the frequency. The latter is responsible for the frequency-dependence of the former. The parallel resistance is the apparent one involved inevitably in ac-measurements of the capacitance. Values of the capacitance are independent of concentration of $\mathrm{KCl}$ in the domain from $0.1 \mathrm{mM}$ to $3 \mathrm{M}$.
\end{abstract}

key words, Nyquist plot of ac impedance; constant phase elements; capacitance and resistance of electric double layer; frequency dispersion of capacitance;

\footnotetext{
* Corresponding author, phone +81776278665 , fax +81 776278750

e-mail kaoki@u-fukui.ac.jp (K. Aoki)
} 


\section{Introduction}

Capacitances of electric double layers are known to exhibit dependence on ac-frequency even without faradaic reactions [1-3]. Some reasons for the frequencydependence have been proposed to be dielectric loss [1], cracks on electrodes and/or insulators [2], adsorption [4-7], surface roughness [8-11], fractal dimensions of electrodes [12,13], cell geometry [14], lateral charge spreading in the double layer [15], harmonic components [16], and heterogeneities on the atomic scale [17]. The frequency-dependence has been diminished at single crystal surfaces [18], but has still been observed $[19,20]$. It gets remarkable when adsorption occurs at single crystal surfaces $[21,22]$.

Values of double layer capacitances depend on equivalent circuits employed for the data analysis. Even if an equivalent circuit is suitable for curve fitting, it is not always unique, according to the IUPAC recommendation for equivocal equivalent circuits [23]. It is desirable to express the frequency dispersion of capacitances in a simple form. A measure of the dispersion is the parameter, $\alpha$, of the constant phase element (CPE) [24-27], which is given in the impedance $Z$ by

$$
\begin{aligned}
& Z=R_{\mathrm{S}}+\left(1 / Z_{\mathrm{F}}+Y_{\mathrm{CPE}}\right)^{-1} \\
& Y_{\mathrm{CPE}}=Q(i \omega)^{\alpha}
\end{aligned}
$$

where $R_{\mathrm{S}}$ is the ohmic resistance in series with the faradaic impedance $Z_{\mathrm{F}}$ of the electrode reaction in parallel with the admittance $Y_{\mathrm{CPE}}$ of the CPE, $i$ is the imaginary unit, and $Q$ is a constant. When no Faradaic reaction is present $\left(Z_{\mathrm{F}} \rightarrow \infty\right)$, Eq. (1) and (2) are reduced to $Z-R_{\mathrm{s}}=Q^{-1}(i \omega)^{-\alpha}$. The in-phase component, $Z_{1}$ and the out of phase one, $Z_{2}$, in $Z$ are written as

$$
\begin{aligned}
& Z_{1}-R_{\mathrm{S}}=Q^{-1} \omega^{-\alpha} \cos (\alpha \pi / 2) \\
& Z_{2}=-Q_{-1} \omega^{-\alpha} \sin (\alpha \pi / 2)
\end{aligned}
$$


The impedance at $\alpha=1$ is the ideal series combination of $R_{\mathrm{s}}$ and the capacitance, whereas that at $\alpha=0$ corresponds only to the resistance circuit, $R_{\mathrm{s}}+1 / Q$. Taking the ratio in Eq. (3) leads to

$-Z_{2} /\left(Z_{1}-R_{\mathrm{S}}\right)=\tan (\alpha \pi / 2)$

If $R_{\mathrm{s}}$ is much smaller than $Z_{1}$, the Nyquist plot for polarized interfaces should fall on a proportional line. The proportionality in wide frequency domains has been observed at aluminum electrodes [28], at the $\mathrm{Au}(210)$ in solutions of potassium halides [29], at the gold electrode in sulfuric acid [30], at platinum electrode in $\mathrm{KCl}$ solution [31], conducting polymer-coated electrodes [32,33], and $\mathrm{Li}^{+}$insertion to $\mathrm{Nb}_{2} \mathrm{O}_{5}$ [11]. Then, values of $\alpha$ for the proportionality have been determined unequivocally, independent of frequency. They have also been evaluated from slope of the plot of logarithmic out of phase components vs. $\log (\omega)[17,28,30,34,35]$. Plot of in-phase components, i.e. $\log \left(Z_{1}\right.$ - $\left.R_{\mathrm{s}}\right)$ vs. $\log (\omega)$, should exhibit a similar variation. However, few authors have paid attention to the latter dependence [36,37], probably because the in-phase component is less dependent on frequency than the out of phase. Introduction of equivalent circuits is helpful for understanding approximately the CPE behavior [38-46].

In order to examine frequency dependence in the in-phase, it is necessary at first to evaluate solution resistance accurately. The simplest cell for evaluating solution resistance is a rectangular or a cylindrical cell involving parallel plate electrodes. However, boundaries between the electrodes and the insulator in these cells provide irreproducible capacitance values owing to immersion of solutions in cracks or insufficient shielding [47]. Possible electrode geometry without shielding is two parallel thin wires immersed in solution. The present work deals with this electrode geometry in order to evaluate cell resistance independent of capacitance by means of both the frequency-dependence of the in-phase component and the theoretical estimation from 
the cell geometry. The frequency dependence will be demonstrated to be responsible for logarithmic dependence of the capacitance on frequency. The present report does not include searching a reason for the dispersion of capacitances.

\section{Experimental}

All the chemicals were of analytical grade. Solutions were prepared with ion-exchanged distilled water.

Working electrodes were platinum wires $0.1 \mathrm{~mm}$ in diameter. They were wound around a tungsten wire shielded in a glass capillary tube, and were bonded with conducting paste. They were soaked in acetone and rinsed with distilled water. One of them was fixed vertically with a beam, and the other was mounted on an optical $x-y$ positioner so that the distance, $d$, between the two wires was adjusted, as illustrated in Fig. 1. The positioner was put on a jack so that both tips of the wires were on the same level. The active length, $L$, of the electrodes was controlled with a lift for the aqueous solution. Values of $d$ and $L$ were read through an optical microscope. A typical value of $L$ was $10 \mathrm{~mm}$. Aqueous solution rose from the aqueous surface on the wire by the surface tension. The rise was at most $0.2 \mathrm{~mm}$ from an optical microscope. The error of surface area of the electrode was less than $2 \%$.

The potentiostat was Compactstat (Ivium, Netherlands), equipping a lock-in amplifier. Applied alternating voltage was $10 \mathrm{mV}$ in amplitude. Solution was deaerated by nitrogen gas for $15 \mathrm{~min}$ before electrochemical measurements.

Delay of the potentiostat was examined by a series combination of a carbon resistance $(1,10 \mathrm{k} \Omega)$ and a film capacitor $(0.1 \mu \mathrm{F})$ for a frequency range from $1 \mathrm{~Hz}$ to $10 \mathrm{kHz}$. No abnormality was observed so far as $\left|Z_{2}\right| / Z_{1}>0.04$. For frequencies larger than $\left|Z_{2}\right| / Z_{1}<0.04,\left|Z_{2}\right|$ values were over estimated by a few percentages. Most 
experimental conditions of the double layer measurements were in the domain of $\left|Z_{2}\right| / Z_{1}$ $>0.04$.

\section{Results and Discussion}

\subsection{Nyquist plot}

Figure 2(a) shows cyclic voltammograms of $0.5 \mathrm{M}\left(=\mathrm{mol} \mathrm{dm}{ }^{-3}\right) \mathrm{KCl}$ solution in nitrogen atmosphere at the two-wire electrode. The voltammograms were symmetric with respect to the origin because of measurements for the two-electrode system at geometrically symmetric electrode. Currents at potential $|E|<0.14 \mathrm{~V}$ were proportional to the potential scan rates. They must be capacitive current. Voltammograms in $0.2 \mathrm{mM}$ $\mathrm{Fe}(\mathrm{CN})_{6}{ }^{3-}+0.2 \mathrm{mM} \mathrm{Fe}(\mathrm{CN})_{6}{ }^{4-}+0.5 \mathrm{M} \mathrm{KCl}$ increased by 100 times owing to the redox reaction, as shown in Fig. 2(b). Even if any Faradaic current is included in the voltammograms in the $\mathrm{KCl}$ solution (Fig. 2(a)) as impurity of the solution, the concentration of impurity causing the Faradaic current should be less than $2 \mu \mathrm{M}$.

Figure 3(A) shows the Nyquist plot at the parallel Pt wire electrodes in $0.5 \mathrm{M} \mathrm{KCl}$ solution. Some other wire electrodes exhibited almost the common Nyquist plots. This is an advantage of unshielded electrodes. Nyquist plots did not vary with whether electrodes were immersed in nitrohydrochloric acid before ac-measurements or not. The linear plot in Fig. 3(A) is different from a conventional shape of the combination of a semicircle and a line. However, straight line-like plots have been reported $[11,22,28,29,3133,48]$ for work on the $\mathrm{CPE}$ behavior. If $Z_{1}$ represents solution resistance, a change in frequency should vary only $Z_{2}$ values, retaining $Z_{1}$ values. Then the plot must fall on a vertical line. The observed variation of $Z_{1}$ with the frequency indicates that $Z_{1}$ should include contributions of the double later capacity. This corresponds to the CPE behavior. 
When Eq. (4) is applied to the slope in Fig. 3 on the assumption of neglected solution resistance, we obtain $\alpha=0.95$ for frequencies more than $50 \mathrm{~Hz}$. Since $\alpha=1$ and 0 correspond to only an ideal capacitor and only an ideal resistor, respectively, the impedance at the twin platinum electrode is close to a capacitor. In order to determine $\alpha$ more accurately, we evaluated the solution resistance from the extrapolation of $Z_{1}$ to zero $Z_{2}$ for infinite frequency [49], denoted by $R_{\mathrm{s}, \mathrm{N}}$, as is shown in Fig. 3(B).

\subsection{Solution Resistance}

$Z_{1}$ seems to include information of capacitance, and hence $R_{\mathrm{s}, \mathrm{N}}$ may not stand accurately for the solution resistance. A technique of estimating how much $R_{\mathrm{s}, \mathrm{N}}$ represents the solution resistance is to examine dependence of $R_{\mathrm{s}, \mathrm{N}}$ on geometry of the electrodes. Solution resistance between two parallel wires is not expressed by a simple proportionality to $d$. We derive here analytical expressions for the resistance between thin parallel wires.

A model of the resistance is a pair of parallel cylindrical long wires $a$ in radius, separated by the distance, $d$, between the two centers of the cylinders. Voltage $V$ is applied between the two wires immersed in solution with resistivity, $\rho$. We put the cross-section of the wires (circles) on the coordinate of Fig. 4. If current flows out isotropically from a circle located at the origin and flow into the infinity two-dimensionally, the current density vector, $\boldsymbol{j}$, at the radial distance vector, $\boldsymbol{r}$, is satisfied with $2 \pi \boldsymbol{r} \cdot \boldsymbol{j}=$ constant, where the dot denotes the inner product. When the length of the wire is $L$, the total current $I$ is given by $2 \pi a j L$. Consequently, we have $2 \pi r$

.j $L=I$. When the vector of the current density, $j_{1}$, flows out from the circle at $x=-d / 2$ into the infinity independently from the circle at $x=d / 2$, it is expressed by

$$
2 \pi(\boldsymbol{r}+\boldsymbol{d} / 2) \cdot \boldsymbol{j}_{1} L=I
$$


Similarly the vector of the current density, $\boldsymbol{j}_{2}$, flowing out from the infinity enters the circle at $x=d / 2$ independently from the circle at $x=-d / 2$, it is given by

$$
2 \pi(\boldsymbol{r}-\boldsymbol{d} / 2) \cdot \boldsymbol{j}_{2} L=I
$$

Taking the inner product of Eq. (5) and (6) with $\boldsymbol{r}+\boldsymbol{d} / 2, \boldsymbol{r}-\boldsymbol{d} / 2$, respectively, yields

$$
\boldsymbol{j}_{1}=\frac{(\boldsymbol{r}+\boldsymbol{d} / 2) I}{2 \pi|\boldsymbol{r}+\boldsymbol{d} / 2|^{2} L}, \quad \boldsymbol{j}_{2}=\frac{(\boldsymbol{r}-\boldsymbol{d} / 2) I}{2 \pi|\boldsymbol{r}-\boldsymbol{d} / 2|^{2} L}
$$

From Eq. (7), the total current density, $\boldsymbol{j}=\boldsymbol{j}_{1}+\boldsymbol{j}_{2}$, is given by

$$
\boldsymbol{j}=\frac{I}{2 \pi L}\left(\frac{(\boldsymbol{r}+\boldsymbol{d} / 2)}{|\boldsymbol{r}+\boldsymbol{d} / 2|^{2}}+\frac{(\boldsymbol{r}-\boldsymbol{d} / 2)}{|\boldsymbol{r}-\boldsymbol{d} / 2|^{2}}\right)
$$

Electric potential in solution, $\phi$, is correlated with $j$ through Ohm's law, $j=-(1 / \rho)(\mathrm{d} \phi / \mathrm{d} r)$. Applying it to Eq. (8) and integrating the resulting equation along a current line yields the potential difference, $V$, between the two electrodes. If we select a current line on the $x$-axis, and carry out the integration, we obtain

$$
V=\rho \int_{-d / 2+a}^{d / 2-a} j \mathrm{~d} x=\frac{I \rho}{\pi L} \ln \left(\frac{d}{a}-1\right)
$$

Then the solution resistance is expressed by

$$
R_{\mathrm{s}, \mathrm{G}}=V / I=\frac{\rho}{\pi L} \ln \left(\frac{d}{a}-1\right)
$$

Since the integral contour in Eq. (9) was taken to be the shortest path, the resistance should be underestimated. It is important to note that the resistance is proportional to $\ln (d / a-1)$ rather than $d$.

The underestimation of Eq. (10) was corrected by means of the numerical computation of the two-dimensional Laplace equation for $\phi$. The numerical solution was obtained by the finite element method. The boundary conditions were zero flux on all the boundaries except on the electrodes. Figure 4 shows an example of the divided 
triangular elements. The software was home-made. Potential profiles were computed, and they are shown as gradient colors in Fig. 4. Fluxes evaluated on the electrode from the profiles were summed to yield the total current, and hence the conductance. The computed dimensionless resistance, $R_{\mathrm{s}, \mathrm{G}} L / \rho$, was plotted against $\ln (d / a-1)$ in Fig. 5. They were slightly larger than Eq. (10) (solid line in Fig. 5), as was predicted. They fell on the line 1.25 times as large as the line of Eq. (10) for $\ln (d / a-1)>1.5$. Then the resistance for monovalent electrolyte with concentration $c$ is given by

$$
R_{\mathrm{s}, \mathrm{G}}=1.25 \frac{\ln (d / a-1)}{\pi L c\left(\lambda_{+}+\lambda_{-}\right)}=0.916 \frac{\log (d / a-1)}{L c\left(\lambda_{+}+\lambda_{-}\right)}
$$

where $\lambda_{+}$and $\lambda_{-}$are molar conductivity of the mono-cation and the mono-anion, respectively.

Values of $R_{\mathrm{s}, \mathrm{N}}$, were plotted against $\log (d / a-1)$ for some concentrations of $\mathrm{KCl}$ in Fig. 6. Although they are approximately linear to $\log (d / a-1)$, all the plots for concentrations from 0.001 to $3 \mathrm{M}$ had positive values of intercepts. Furthermore, they are slightly smaller than the lines obtained from Eq. (11) for all the concentrations. The smaller shift will be explained in terms of the frequency-dependence of the double layer capacity in section 3.3 .

Figure 7 shows dependence of $Z_{1}$ at some frequencies on $\log (d / a-1)$. The plot for a given frequency fell on a line with the common slope, which is similar to the value of the slope in Eq. (11) (Fig. 7(d)), $12 \Omega$ for $\lambda_{+}=7.35 \times 10^{-3} \mathrm{~S} \mathrm{~m}^{2} \mathrm{~mol}^{-1}$ and $\lambda_{-}=7.63 \times 10^{-3} \mathrm{~S}$ $\mathrm{m}^{2} \mathrm{~mol}^{-1}$. In contrast, the intercept at $\log (d / a-1)=0$, i.e. $d=2 a$, means the resistance that would appear if the two electrodes were to come in contact each other. This resistance should be located at the interface or included in the double layer. It increases with a decrease in frequencies.

\subsection{Parallel equivalent circuit}


The above result infers that the observed double layer capacitance, $C_{\mathrm{d}}$, includes not only the double layer capacitance, $C_{\mathrm{p}}$, but also the resistance, $R_{\mathrm{p}}$, in a parallel combination of the equivalent circuit, as illustrated in Fig. 8(A). Two parallel combinations of $C_{\mathrm{p}}$ and $R_{\mathrm{p}}$, mean two wire electrodes. The measured quantities, $Z_{1}$ and $Z_{2}$ in Fig. 8(B), do not directly correspond to the solution resistance, $R_{\mathrm{s}}$, and $C_{\mathrm{d}}$. The two equivalent circuits can be converted through

$$
Z_{1}+i Z_{2}=R_{\mathrm{s}}+\frac{2}{1 / R_{\mathrm{p}}+i \omega C_{\mathrm{p}}}
$$

Equating the real parts on the both hand sides yields

$$
Z_{1}-R_{\mathrm{s}}=\frac{2 R_{\mathrm{p}}}{1+\left(\omega C_{\mathrm{p}} R_{\mathrm{p}}\right)^{2}}, \quad Z_{2}=\frac{-2 \omega C_{\mathrm{p}} R_{\mathrm{p}}^{2}}{1+\left(\omega C_{\mathrm{p}} R_{\mathrm{p}}\right)^{2}}
$$

$R_{\mathrm{p}}$ and $C_{\mathrm{p}}$ are extracted in the following forms;

$$
R_{\mathrm{p}}=\frac{\left(Z_{1}-R_{\mathrm{s}}\right)^{2}+Z_{2}^{2}}{2\left(Z_{1}-R_{\mathrm{s}}\right)}, C_{\mathrm{p}}=\frac{-2 Z_{2}}{\omega\left\{\left(Z_{1}-R_{\mathrm{s}}\right)^{2}+Z_{2}^{2}\right\}}
$$

We evaluated $R_{\mathrm{p}}$ and $C_{\mathrm{p}}$ by use of $R_{\mathrm{s}, \mathrm{N}}$ for $R_{\mathrm{s}}$ from $Z_{1}$ and $Z_{2}$ at various values of $d / a$. Figure 9 shows dependence of $\log \left(R_{\mathrm{p}}\right)$ and $C_{\mathrm{p}}$ for some values of frequency. Values of $R_{\mathrm{p}}$ and $C_{\mathrm{p}}$ were independent of $d / a$, indicating that they should have interfacial properties without including any information of $d$.

Values of $R_{\mathrm{p}}$ and $C_{\mathrm{p}}$ averaged over $d / a$ are plotted against the frequency in Fig. 10 and 11 , respectively. The logarithm of $R_{\mathrm{p}}$ shows a linear relation to $\log (f)$ for $f<10^{4.5} \mathrm{~Hz}$ with a slope -1 . The plots varied negligibly with concentrations of $\mathrm{KCl}$ in the domain from $0.005 \mathrm{M}$ to $3 \mathrm{M}$. The empirical equation for $R_{\mathrm{p}}$ is given by

$R_{\mathrm{p}}=1.8 \times 10^{6} / f$

with a unit in $\Omega$. In contrast, the averaged values of $C_{\mathrm{p}}$ decrease linearly with the logarithms of the frequency. This type of the decrease resembles that of electrolyte capacitors $[50,51]$. The slope and the intercept were almost independent of the 
concentration of $\mathrm{KCl}, c$. Letting the concentration variation of the intercept (at $1 \mathrm{~Hz}$ ) be $\left(C_{\mathrm{p}}\right)_{f=1}$, we can express empirically the dependence of $C_{\mathrm{p}}$ on $\log (f)$ as $C_{\mathrm{p}}=\left(C_{\mathrm{p}}\right)_{f=1}-1.20 \times 10^{-7} \log (f)$

where the unit of $C_{\mathrm{p}}$ is Farad.

Figure 12 shows the variation of $\left(C_{\mathrm{p}}\right)_{f=1}$ with $c$. Double layer capacities are predicted intuitively to increase with an increase in concentrations of ions because ions have thought to play a significant role in capacitances. The Gouy-Chapman theory mentions that $C_{\mathrm{d}}$ is proportional to $c^{1 / 2}$ (Fig.12(a)), whereas the ion-cell model predicts the proportionality to $c^{1 / 3}$ (Fig.12(b)) [52]. However, the present experimental data (Fig. 12) shows concentration-independence of $\left(C_{\mathrm{p}}\right)_{f=1}$ within experimental errors. The average value of $\left(C_{\mathrm{p}}\right)_{f=1}$ is $(1.10 \pm 0.04) \mu \mathrm{F}$ or $(34 \pm 2) \mu \mathrm{F} \mathrm{cm}$. The independence indicates whether the ions $\left(\mathrm{K}^{+}\right.$and $\left.\mathrm{Cl}^{-}\right)$must be accumulated on the electrode by the electric tension of the ions to the electrode [52] or the water molecules play a significant role in the capacitance, like Stern's model. The independence has been observed for polarized mercury electrodes by Grahame [53].

We obtained the impedance of fluoride solution by the same method as for chloride. All the variations were almost the same as for chloride (Fig. 3, 9,10,11). Fig. 12 shows the plot of $\left(C_{\mathrm{p}}\right)_{f=1}$ against concentrations of KF. No concentration-variation was found.

When alternating voltage, $V_{0} \mathrm{e}^{i \omega t}$ at angular velocity $\omega$ is applied to an ideal capacity, $C_{\text {ideal }}$, the responding current is expressed by $I=\mathrm{d}\left(C_{\text {ideal }} V\right) / \mathrm{d} t=i \omega C_{\text {ideal }} V$. Then the current exhibits a phase shift of $\pi / 2$. If the capacitance $C$ depends on the frequency, the current is expressed by

$$
I=\frac{\mathrm{d}(C(\omega) V(t))}{\mathrm{d} t}=C(\omega) \frac{\mathrm{d} V(t)}{\mathrm{d} t}+V(t) \frac{\partial C(\omega)}{\partial \omega} \frac{\mathrm{d} \omega}{\mathrm{d} t}
$$

The first term on the lhs is $i \omega C V$. Since the time is equivalent to $1 / \omega$, we have $\mathrm{d} \omega / \mathrm{d} t=$ $-1 / t^{2}$. Replacing $C$ by $C_{\mathrm{p}}$, inserting Eq. (16) into Eq. (17) and carrying out the integration yields 


$$
I=\left(i \omega C_{\mathrm{p}}+\left(1.20 \times 10^{-7} / 2.3\right) \omega\right) V=\left(i \omega C_{\mathrm{p}}+3.3 \times 10^{-7} f\right) V
$$

This equation suggests the parallel equivalent circuit composed of $C_{\mathrm{p}}$ and the frequency-dependent admittance, $3.3 \times 10^{-7} f$. The latter can be written as a resistance $3 \times 10^{6} / f$, which should be identical with $R_{\mathrm{p}}$ by the definition in Fig. $8(\mathrm{~A})$. Indeed, the parallel resistance is inversely proportional to $f$, as shown in Eq. (15). The proportionality constant is not far from that in Eq. (15). The difference may be ascribed to the assumption of $t=1 / 2 \pi f$. Since $\mathrm{d} C / \mathrm{d} t$ in Eq. (17) is an in-phase component, it is the non-zero values of $\mathrm{d} C / \mathrm{d} t$ that provokes the parallel resistance as if $R_{\mathrm{p}}$ might exist in the double layer.

We explain the experimental result, $R_{\mathrm{s}, \mathrm{N}}<R_{\mathrm{s}, \mathrm{G}}$, in Fig. 6. Taking the ratio in Eq. (13) is equal to $-Z_{2} /\left(Z_{1}-R_{\mathrm{s}}\right)=\omega C_{\mathrm{p}} R_{\mathrm{p}}$. The solution resistance geometrically calculated corresponds to a value determined by a direct current, and is approximated as the value at the low frequency, $1 \mathrm{~Hz}$. Then we have Since $C_{\mathrm{p}} \approx\left(C_{\mathrm{p}}\right)_{f=1}$ at low frequency $(<10 \mathrm{~Hz})$, the ratio is approximated to $-Z_{2} /\left(Z_{1}-R_{\mathrm{s}, \mathrm{G}}\right)=\omega C_{\mathrm{p}} R_{\mathrm{p}} \approx 2 \pi\left(3 \times 10^{6}\right)\left(C_{\mathrm{p}}\right)_{f=1}$

In contrast, the solution resistance by the Nyquist plot for large frequency, e.g. $f_{\mathrm{N}}=10^{5}$ $\mathrm{Hz}$, makes the ratio to yield

$$
-Z_{2} /\left(Z_{1}-R_{\mathrm{s}, \mathrm{N}}\right)=\omega C_{\mathrm{p}} R_{\mathrm{p}} \approx 2 \pi\left(3 \times 10^{6}\right)\left[\left(C_{\mathrm{p}}\right)_{f=1}-1.2 \times 10^{-7} f_{\mathrm{N}}\right]
$$

Comparison Eq. (19) with Eq. (20) yields obviously

$$
-Z_{2} /\left(Z_{1}-R_{\mathrm{s}, \mathrm{G}}\right)>-Z_{2} /\left(Z_{1}-R_{\mathrm{s}, \mathrm{N}}\right)
$$

from which we obtain $R_{\mathrm{s}, \mathrm{N}}<R_{\mathrm{s}, \mathrm{G}}$. Consequently, solution resistance evaluated from the Nyquist plot is smaller by the decrease in the capacitance than the geometrically 
evaluated solution resistance. The inequality is caused by the decrease in $C_{\mathrm{p}}$ with an increase in frequency.

Chloride is adsorbed specifically on mercury electrodes, depending on electrode potential [54]. It would be desirable to discuss a possibility of specific adsorption on the platinum electrode. Our potential control was, however, made in the two electrode system without any reference electrode, because we paid attention to accurate determination of solution resistance. Therefore, it is dangerous to discuss effects of potential-depending adsorption on $C_{\mathrm{p}}$ and $R_{\mathrm{p}}$ from the present experimental results.

\section{Conclusions}

The behavior of electric double layers at polarized interfaces in electrolyte solutions more than $0.1 \mathrm{mM}$ is summarized as follows:

A) The Nyquist plot takes approximately a straight line because $Z_{1}$ has roughly the inverse proportion to frequency.

B) $C_{\mathrm{d}}$ is represented by a parallel combination of a capacitance and a resistance.

C) The resistance parallel to the double layer is inversely proportional to frequency.

D) The origin of $R_{\mathrm{p}}$ is ascribed to the linear decrease in $C_{\mathrm{p}}$ on the scale of logarithmic frequency.

E) Values of $C_{\mathrm{p}}$ are independent of concentration of salt.

F) The solution resistance by the Nyquist plot at high frequency is smaller than the geometrically evaluated resistance.

Without frequency-dependence in $C_{\mathrm{d}}, R_{\mathrm{p}}$ might be infinite. Consequently, the electric properties of the double layer could be represented by a series combination of an ideal resistance and an ideal capacitance. The frequency-dependence of $Z_{1}$ is the apparent resistance associated with impedance measurements. If double layer 
capacitances were to be determined by direct current measurements, it might include no resistance component. Application of sinusoidal voltage to the double layer with non-zero values of $\mathrm{d} C / \mathrm{d} t$ provides the parallel resistance unexpectedly. In other words, measurements of double layer capacitance belong to breakdown measurements.

\section{Acknowledgement}

This work was financially supported by Grants-in-Aid for Scientific Research (Grants 22550072) from the Ministry of Education in Japan. 


\section{Figure Captions}

Figure 1. Illustration of the cell and a pair of the wire electrodes, where $L$ is the effective length of the wire electrodes immersed in the solution, and $d$ is the center-to-center distance of the two wires.

Figure 2. Cyclic voltammograms in (a) $0.5 \mathrm{M} \mathrm{KCl}$ solution and (b) $0.2 \mathrm{mM} \mathrm{K}_{3} \mathrm{Fe}(\mathrm{CN})_{6}$ $+0.2 \mathrm{mM} \mathrm{K}_{4} \mathrm{Fe}(\mathrm{CN})_{6}$ at the two parallel Pt wires $0.1 \mathrm{~mm}$ in diameter $10 \mathrm{~mm}$ in length with the distances, $d=2 \mathrm{~mm}$ for scan rate of $10 \mathrm{mV} \mathrm{s}^{-1}$.

Figure 3. Nyquist plot at the two parallel Pt wires $0.1 \mathrm{~mm}$ in diameter $10 \mathrm{~mm}$ in length with the distances, $d=2 \mathrm{~mm}$ in $0.5 \mathrm{M} \mathrm{KCl}$ aqueous solution obtained for (A) low frequencies at (x mark) $5 \mathrm{~Hz}$ and (+ mark) $51 \mathrm{~Hz}$, and (B) high frequencies at (x mark) $1 \mathrm{kHz}$ and (+ mark) $10 \mathrm{kHz} \cdot R_{\mathrm{s}, \mathrm{N}}$ is the value extrapolated for $f \rightarrow \infty$.

Figure 4. Two-dimensional model for potential distribution at the two parallel cylinders for $d / a=20$, and computed potential distribution by the finite element method in the potential field discretized by triangles.

Figure 5. Dependence of the dimensionless resistance, $R L / \rho$, obtained by (circles) the finite element method, by (solid line) Eq. (10) on $\ln (d / a-1)$, by (dashed line) Eq. (11) for the fitting.

Figure 6. Dependence of $R_{\mathrm{s}, \mathrm{N}}\left(=Z_{1}(f \rightarrow \infty)\right)$ determined from the Nyquist plots for concentrations of $\mathrm{KCl}$ (a) 0.01 , (b) 0.03 , and (c) $0.1 \mathrm{M}$ on $\ln (d / a-1)$. The lines are from Eq. (11). The dotted line is the recessed line for (a).

Figure 7. Plots of $Z_{1}$ with $\log (d / a-1)$ for frequencies of (a) $100 \mathrm{~Hz}$, (b) $1000 \mathrm{~Hz}$ and (c) $5000 \mathrm{~Hz}$ in $0,5 \mathrm{M} \mathrm{LCl}$. Line (d) is from Eq. (11). 
Figure 8. Equivalent circuits of (A) series combination $\left(Z_{1}+i Z_{2}\right)$, (B) geometrical assignment of $R_{\mathrm{s}}$ and $C_{\mathrm{d}}$, and (C) really acting combination of $R_{\mathrm{s}}, C_{\mathrm{p}}$ and $R_{\mathrm{p}}$.

Figure 9. Variations of $R_{\mathrm{p}}$ (left axis) and $C_{\mathrm{p}}$ (right axis) in the parallel equivalent circuit with $d / a$ for frequencies of (a) 100 , (b) 760 and (c) $1500 \mathrm{~Hz}$ in $0.5 \mathrm{M} \mathrm{KCl}$ solution for $L$ $=10 \mathrm{~mm}$.

Figure 10. Logarithmic dependence of $R_{\mathrm{p}}$ averaged for $d / a$ on $f$ at $[\mathrm{KCl}]=$ (crosses) 0.01 $\mathrm{M}$, (circles) $0.1 \mathrm{M}$, and (triangles) $0.5 \mathrm{M} \mathrm{KCl}$. The slope of the line is -1 .

Figure 11. Variation of $C_{\mathrm{p}}$ averaged for $d / a$ with $f$ at $[\mathrm{KCl}]=$ (crosses) $0.01 \mathrm{M}$, (circles) $0.1 \mathrm{M}$, and (triangles) $0.5 \mathrm{M} \mathrm{KCl}$.

Figure 12. Variation of $g(c)$ with concentration of $\mathrm{KCl}$ by (circles) experiments, (a) the Gouy-Chapman's theory, and (a) the ion-cell model. 


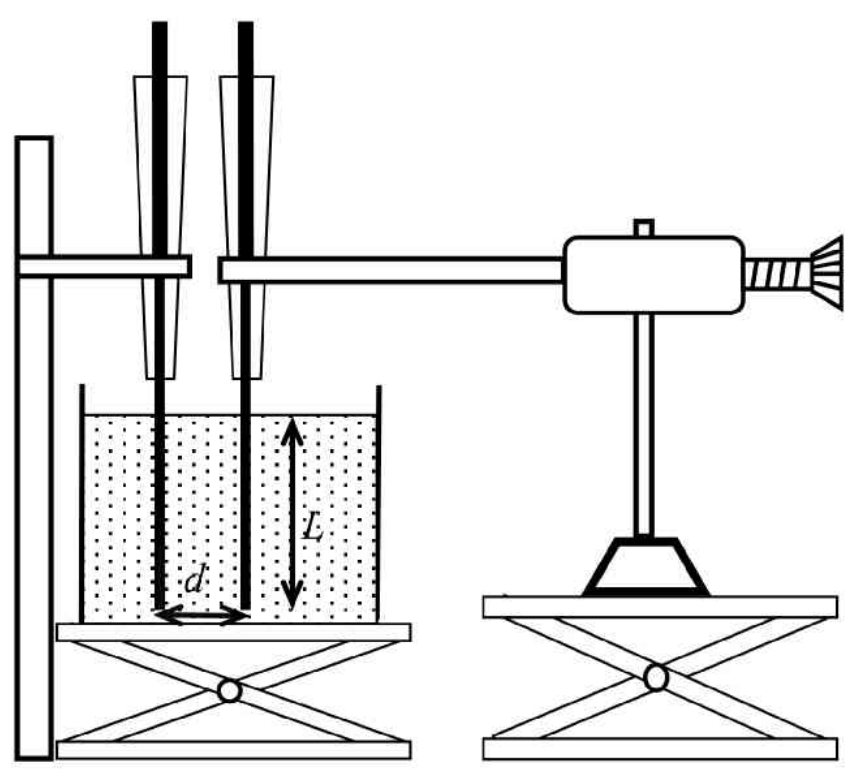

Fig. 1

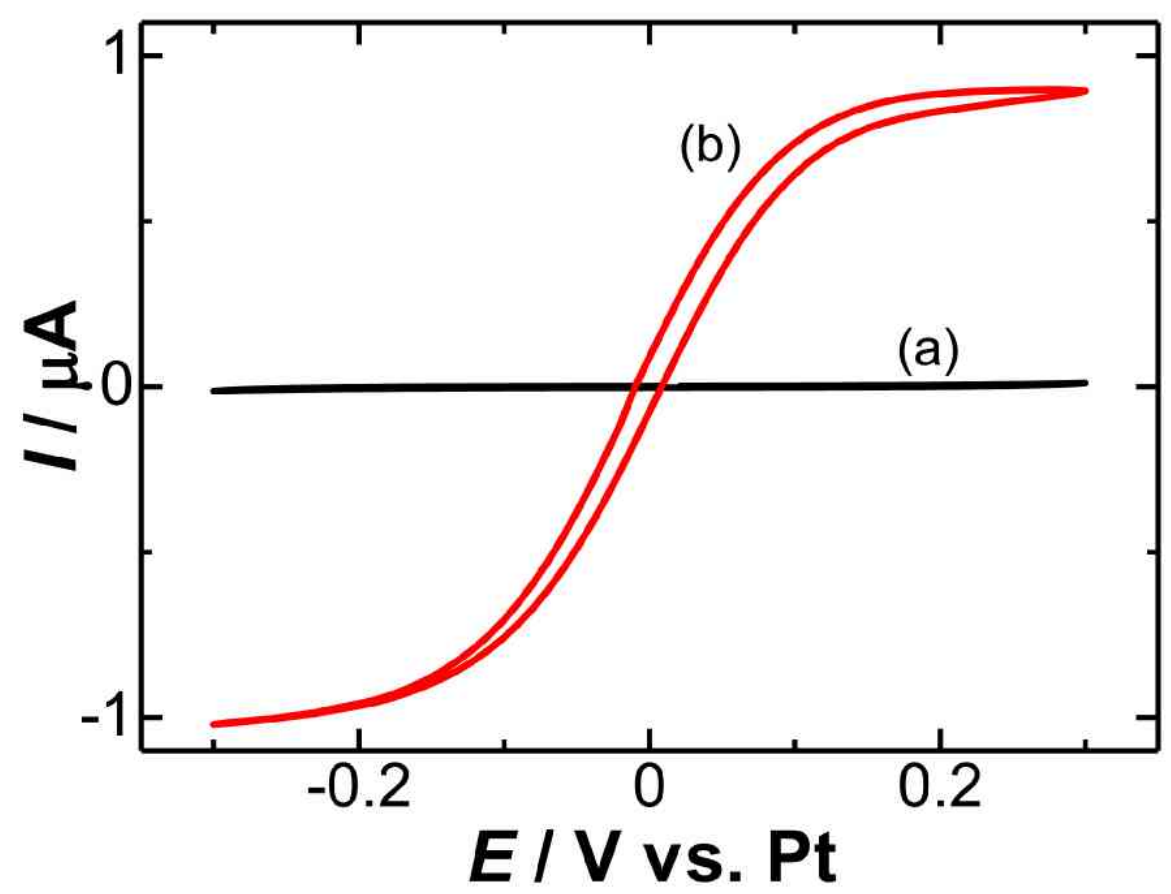

Fig. 2 
Fig. 3(A)
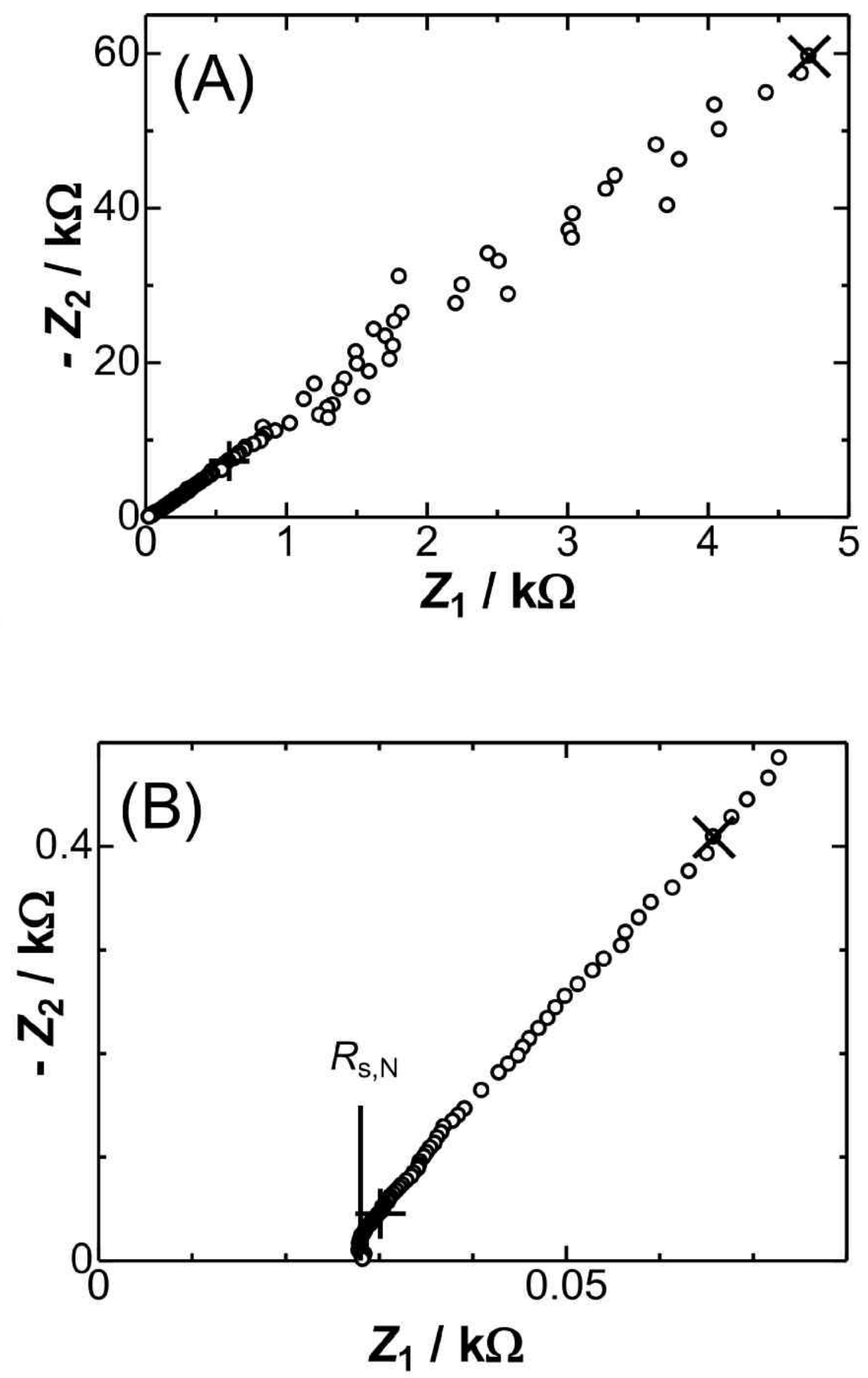

Fig. 3(B) 


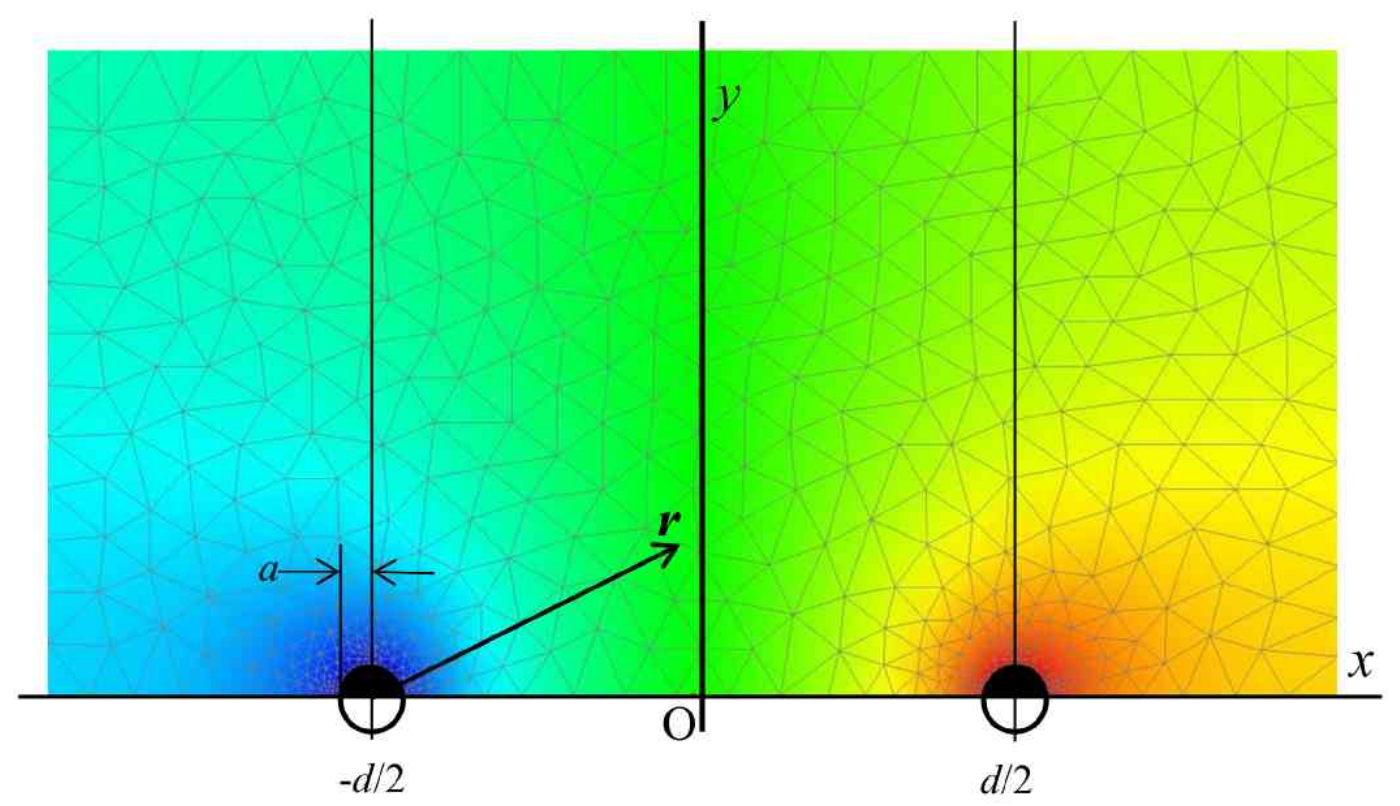

Fig. 4

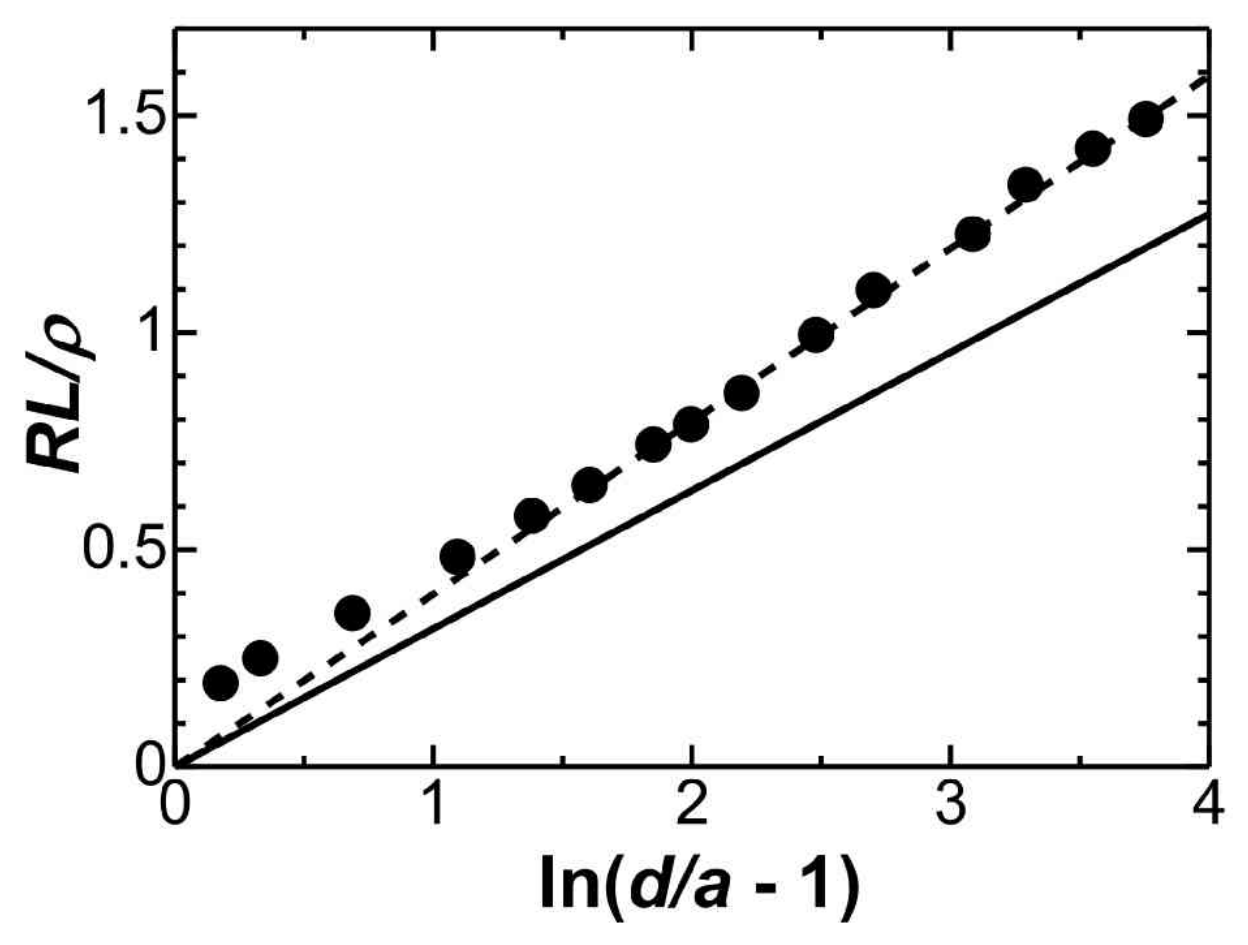

Fig. 5 


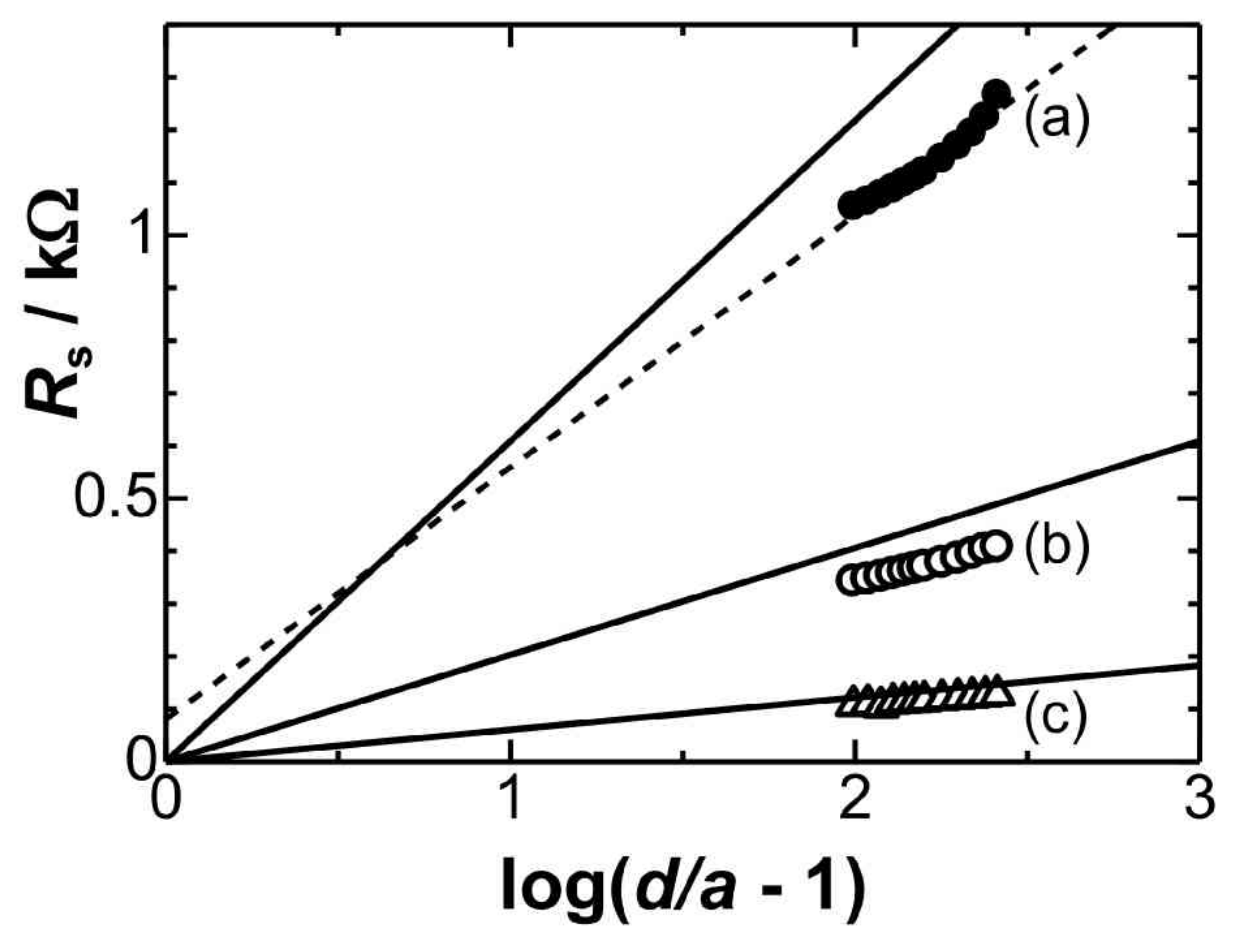

Fig. 6

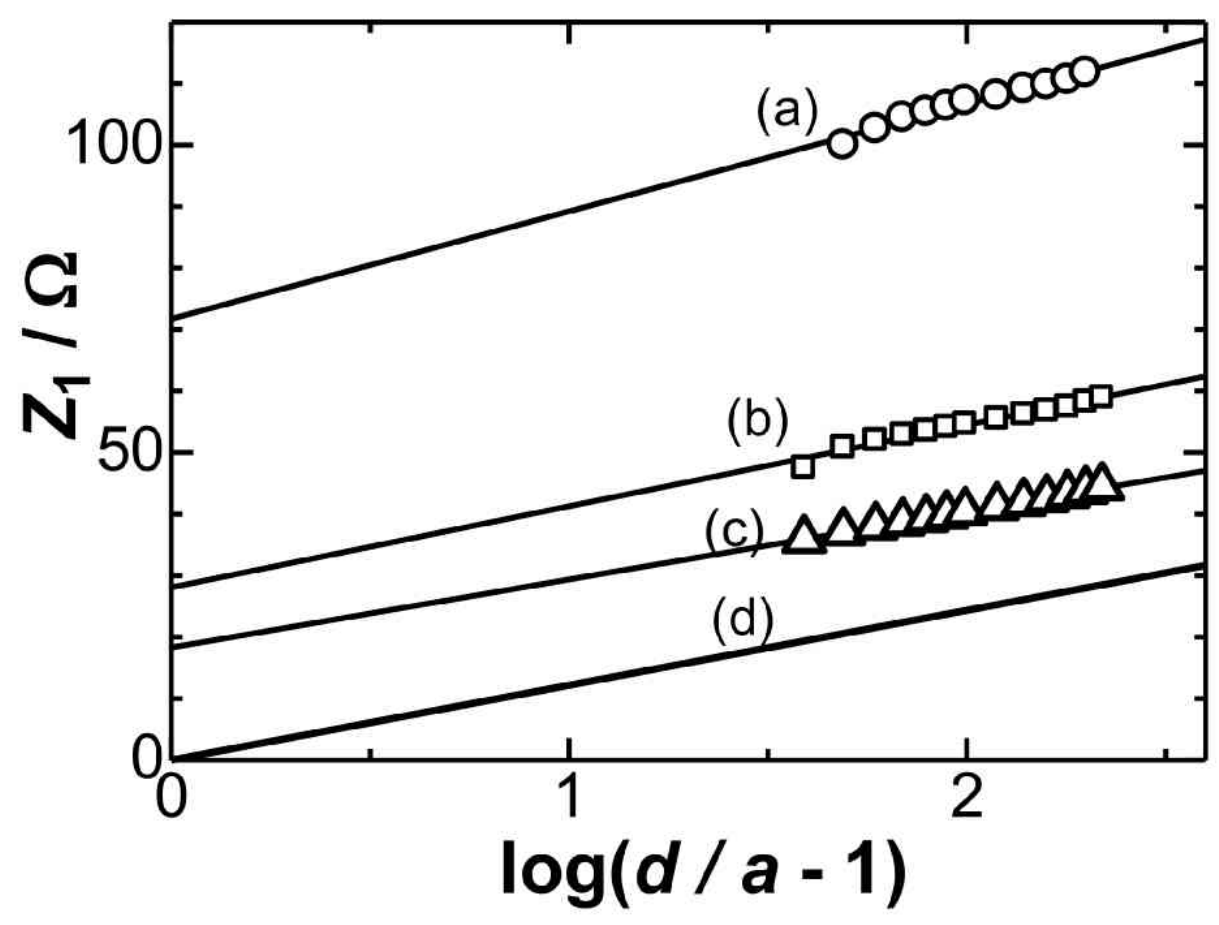

Fig. 7 
(A) measured

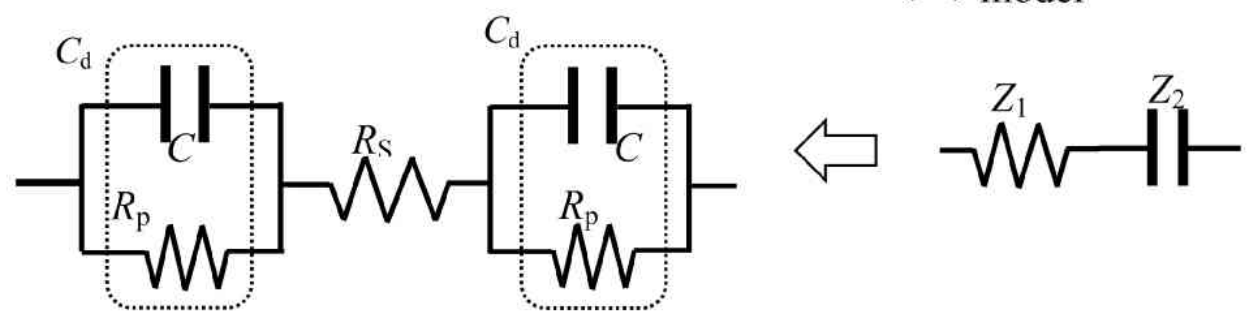

Fig. 8

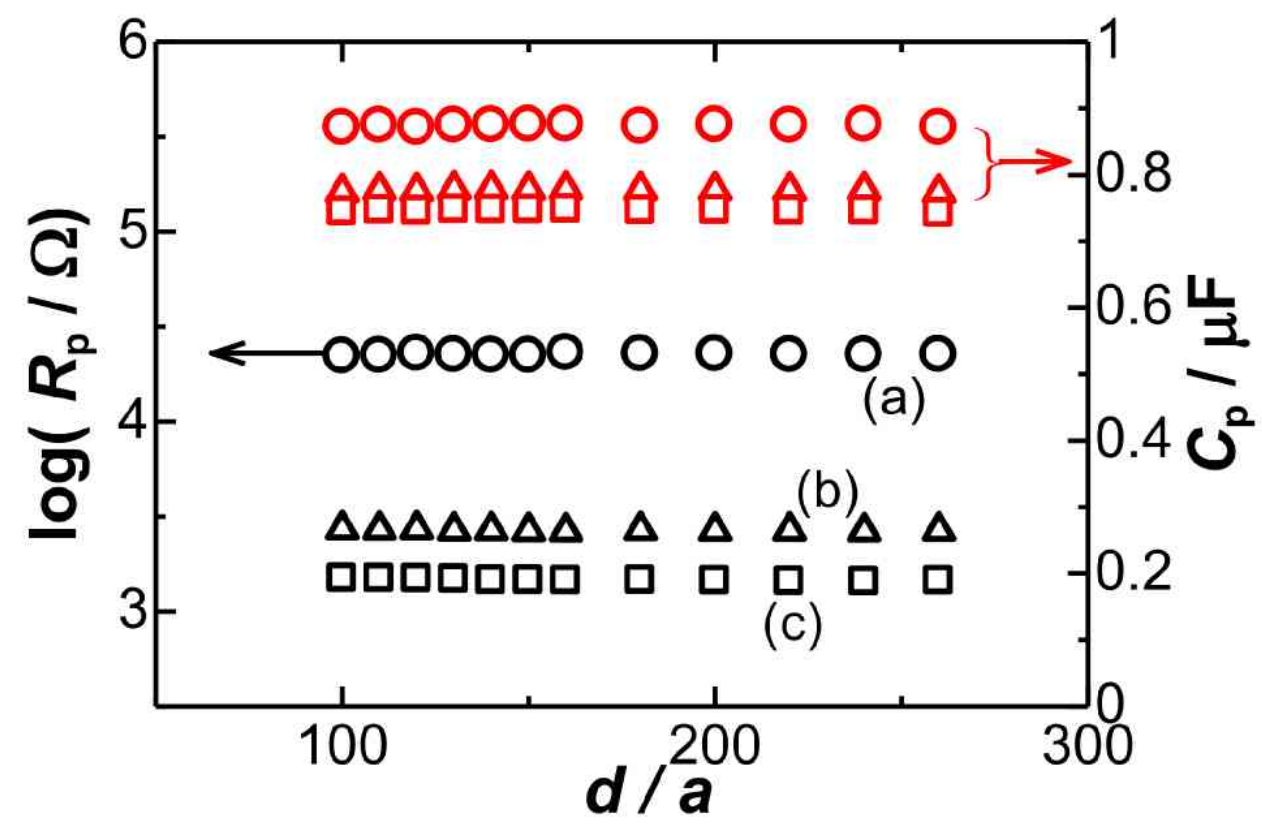

Fig. 9 


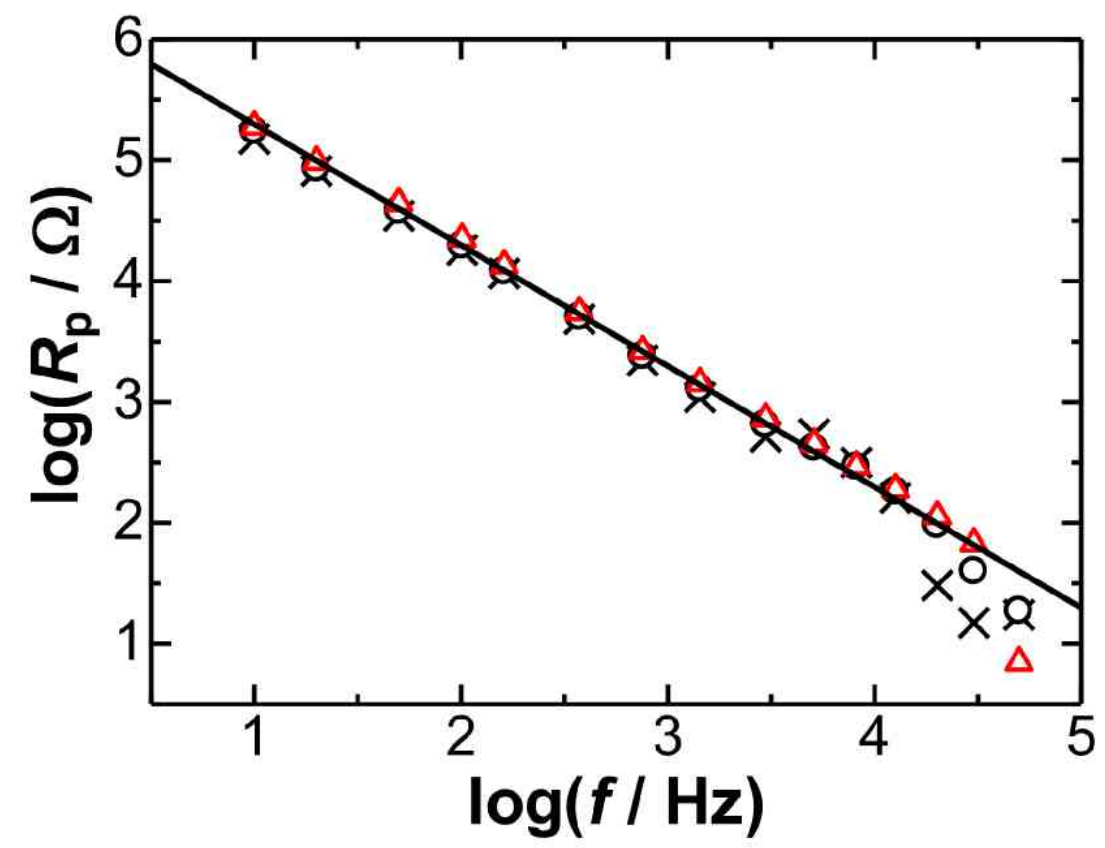

Fig. 10

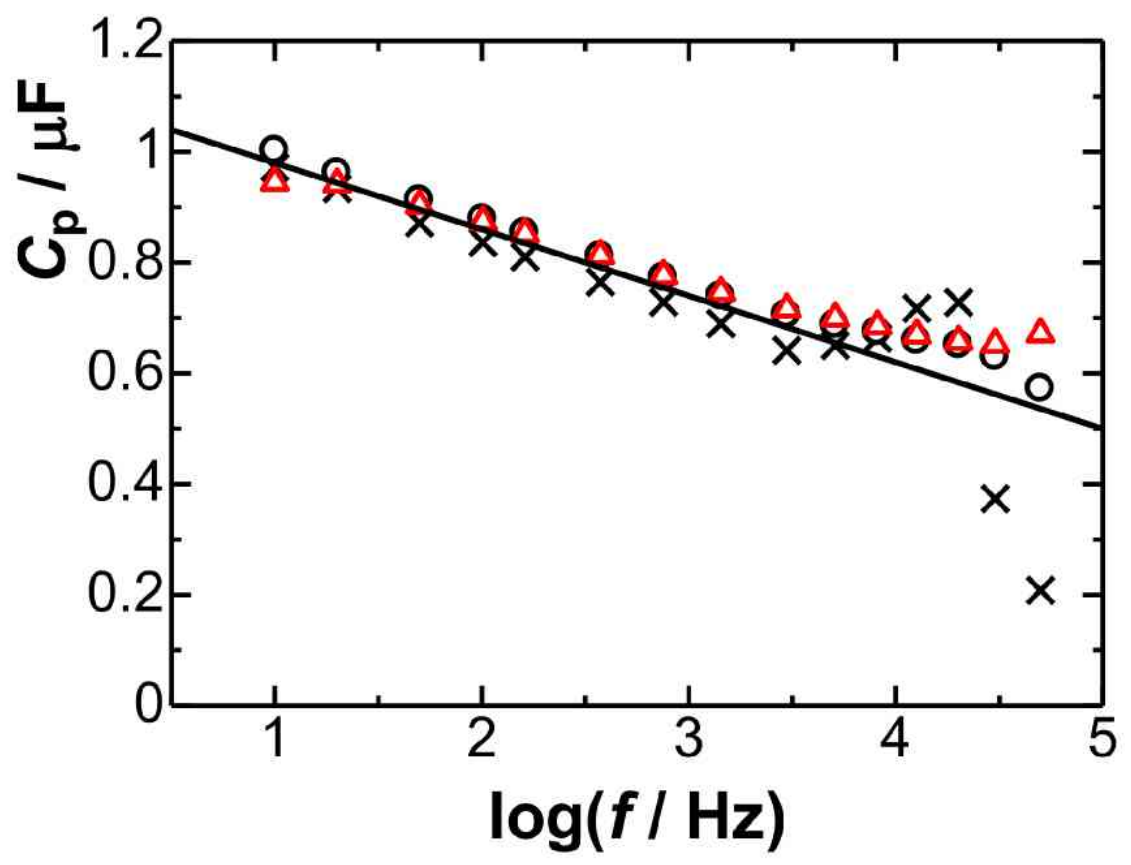

Fig. 11 


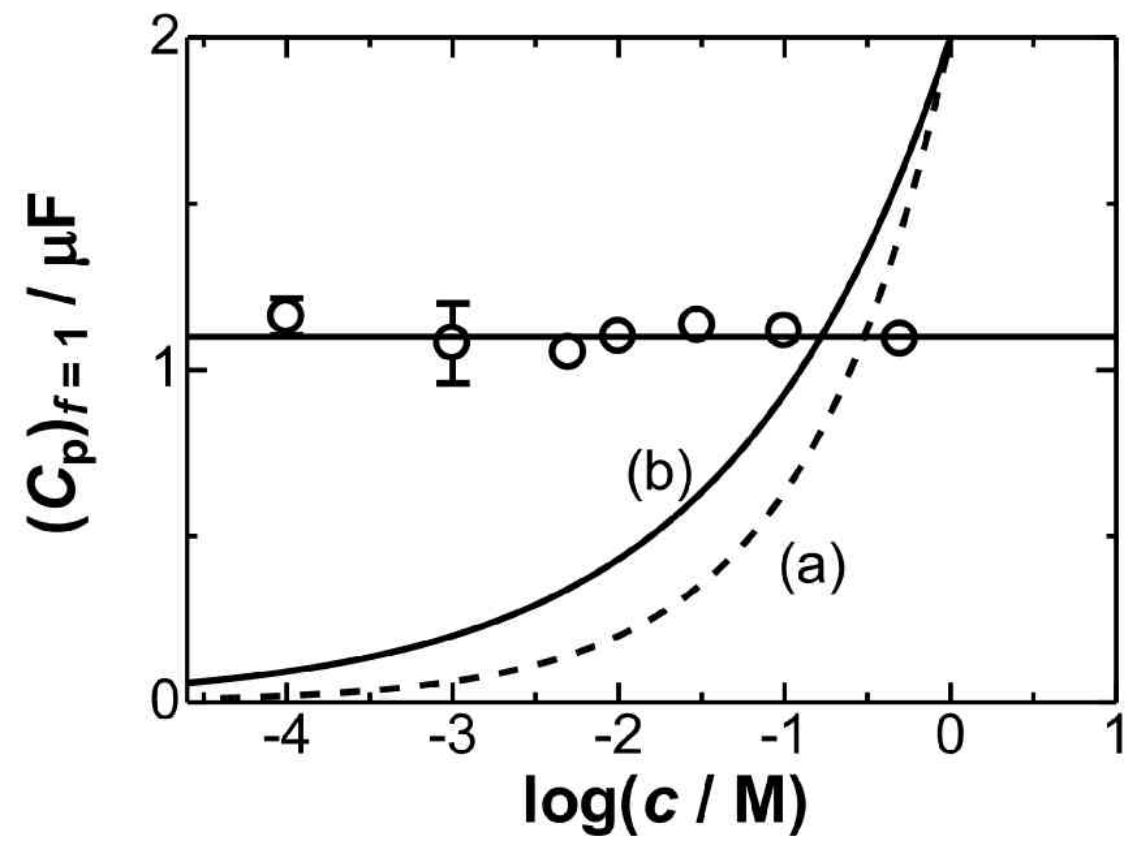

Fig. 12

\section{References}

[1] J. O'M. Bockris, B. E. Conway, J. Chem. Phys. 28 (1958) 707.

[2] A. N. Frumkin, J. Electrochem. Soc. 107 (1960) 461.

[3] L. Ramaley, C. G. Enke, J. Electrochem. Soc. 112 (1965) 947.

[4] W. Lorenz, F. Mockel, Z. Elektrochem. 60 (1956) 507.

[5] R.D. Armstrong, W.P. Rice, H.R. Thirsk, J. Electroanal. Chem. 16 (1968) 517.

[6] R. Leek, N. Hampson, Surf. Tech. 12 (1981) 383.

[7] S.H. Glarum, J.H. Marshall, J. Electrochem. Soc. 126 (1979) 424.

[8] T. Pajkossy, J. Electroanal. Chem. 364 (1994) 111.

[9] S. Cotgreave, N.A. Hampson, P.C. Morgan, M. Welsh, Surf. Tech. 13 (1981) 107.

[10] R. Leek, N. Hampson, Surf. Tech. 7 (1978) 151. 
[11] J. Bisquert, G. G.-Belmonte, P. Bueno, E. Longo, L.O.S. Bulhoes, J. Electroanal. Chem. 452 (1998) 229.

[12] L. Nyikos, T. Pajkossy, Electrochim. Acta 30 (1985) 1533.

[13] B. Sapoval, Solid State Ionics 75 (1995) 269.

[14] R.D. Armstrong, W. P. Race, J. Electroanal. Chem. 33 (1971) 285.

[15] W. Schelder, J. Phys. Chem. 79 (1975) 127.

[16] K. Darowicki, J. Electroanal. Chem. 394 (1995) 81.

[17] Z. Kerner, T. Pajkossy, J. Electroanal. Chem. 448 (1998) 139.

[18] T. Pajkossy, Solid State Ionics, 94 (1997) 123.

[19] A. Hamelin, T. Vitanov, E. Sevastyanov, A. Popov, J. Electroanal. Chem. 145 (1983) 225.

[20] T. Pajkossy, T. Wandlowski, D.M. Kolb, J. Electroanal. Chem. 414 (1996) 209.

[21] V.D. Jovic, R. Parsons, B.M. Jovic, J. Electroanal. Chem. 339 (1992) 327.

[22] R.S. Neves, E.D. Robertis, A.J. Motheo, Appl. Surf. Sci. 253 (2006) 1379.

[23] M. Sluyters-Rehbach, Pure Appl. Chem. 66 (1994) 11831.

[24] A. Lasia, in: R.E. White, B.E. Conway, J.O’M. Bockris (Eds.), Modern Aspects of

Electrochemistry, 32, Kluwer Academic/Plenum Publishers, New York, 1999, p. 143.

[25] L. Nyikos, T. Pajkossy, Electrochim. Acta 30 (1985) 1533.

[26] G.J. Brug, A.L.G. Van Den Eeden, M. Sluyters-Rehbach, J.H. Sluyters, J.

Electroanal. Chem. 176 (1984) 275.

[27] P. Zoltowski, J. Electroanal. Chem. 443 (1998) 149.

[28] J.-B. Jorcin, M. E. Orazem, N. Pbere, B. Tribollet, Electrochim. Acta 51 (2006) 1473 .

[29] R. S. Neves, E. D. Robertis, A. J. Motheo, Electrochim. Acta 51 (2006) 1215.

[30] B. Piela, P. K. Wrona, J. Electroanal. Chem. 388 (1995) 69.

[31] A.A. Isbir-Turan, Z. Üstündağ, A. O. Solak, E. Kılıç, A. Avseven, Thin Solid Films 517 (2009) 2871. 
[32] D.S. Yoo, A. Mahmoudzadeh, E.C.W. Fok, K. Walus, J.D.W.Madden, Electrochim. Acta 56 (2011) 4711.

[33] M.J. Rodı'guez Presa, R.I. Tucceri, M.I. Florit, D. Posadas, J. Electroanal. Chem. $502(2001) 82$.

[34] V. M.-W. Huang, V. Vivier, M.E. Orazem, N. Pébère, B. Tribollet, J. Electrochem. Soc. 154 ( 2007) C99.

[35] M. Drueschler, B. Huber, S. Passerini, B. Roling, J. Phys. Chem. C 114 (2010) 3614.

[36] M.R.S. Abouzari, F. Berkemeier, G. Schmitz, D. Wilmer, Solid State Ionics 180 (2009) 922.

[37] K. Funke, R.D. Banhatti, S. Breuckner, C. Cramer, C. Krieger, A. Mandanici, C. Martiny, I. Ross, Phys. Chem. Chem. Phys. 4 (2002) 3155.

[38] F. Berthier, J.-P. Diard, R. Michel, J. Electroanal. Chem. 510 (2001) 1.

[39] P. Ekdunge, K. Juettner, G. Kreysa, T. Kessler, M. Ebert, W.J.Lorenz, J.

Electrochem. Soc. 138 (1991) 2660.

[40] G. Zheng, B.N. Popov, R.E. White, J. Appl. Electrochem. 27 (1997) 1328.

[41] J.H.O.J. Wijenberg, J.T. Stevels, J.H.W. de Wit, Electrochim. Acta 43 (1997) 649.

[42] T.J. VanderNoot, I. Abrahams, J. Electroanal. Chem. 448 (1998) 17.

[43] B.Y. Yang, K.Y. Kim, Electrochim. Acta 44 (1999) 2227.

[44] R. Tossici, F. Croce, B. Scrosati, R. Marassi, J. Electroanal. Chem. 474 (1999) 107.

[45] M. Ciureanu, H. Wang, J. Electrochem. Soc. 146 (1999) 4031.

[46] S.C. Chung, J.R. Cheng, S.D. Chiou, H.C. Shih, Corros. Sci. 42 (2000) 1249.

[47] D.C. Grahame, J. Amer. Chem. Soc.68 (1946) 301.

[48] A.A. Sagues, S.C. Kranc, E.I. Moreno, Corrs. Sci. 37 (1995) 1097.

[49] A.J. Bard, L.R. Faulkner, Electrochemical Methods; Fundamentals and

Applications, Second edition, Wiley, 2001, pp. 384-386.

[50] F. Meca, A.K. Jonscher, Thin Solid Films 59 (1979) 201. 
[51] F. Climent, R. Capellades, J. Cil, Electrochim. Acta, 38 (1993) 285.

[52] K. Aoki, Electrochim. Acta, 67 (2012) 216.

[53] D.C. Grahame, J. Am. Chem. Soc. 79 (1957) 2093.

[54] D.C. Grahame, J. Amer. Chem. Soc. 71 (1949) 2975. 